DIW BERLIN

Discussion

Papers

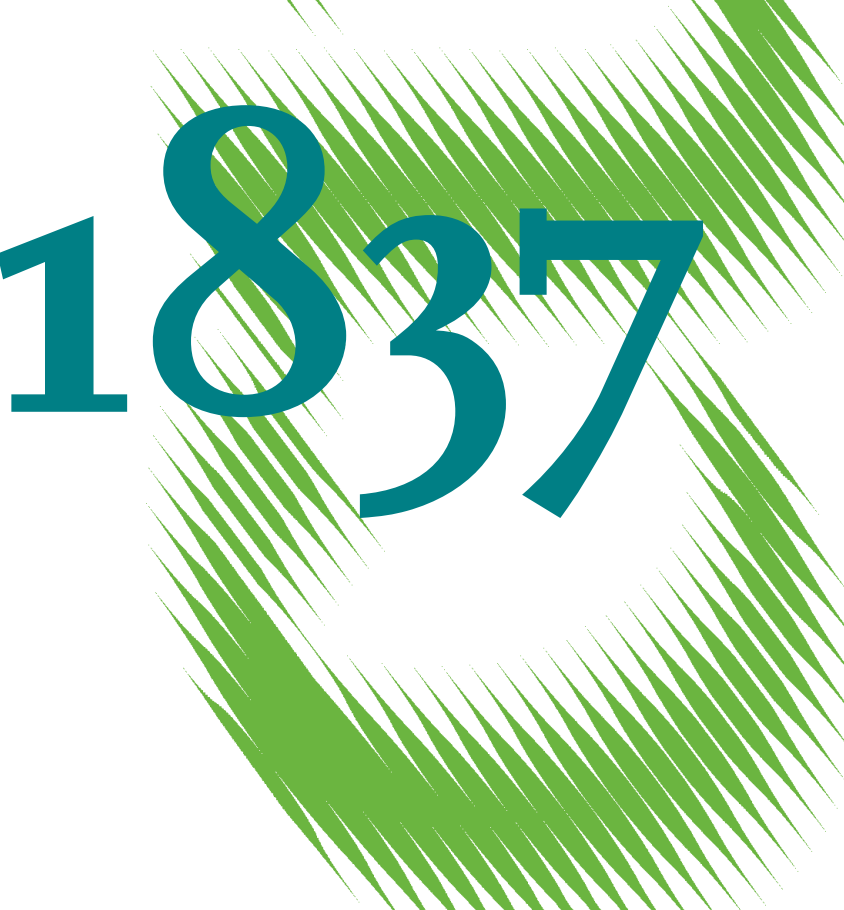

Energy Outlooks Compared: Global and Regional Insights 
Opinions expressed in this paper are those of the author(s) and do not necessarily reflect views of the institute.

IMPRESSUM

(C) DIW Berlin, 2019

DIW Berlin

German Institute for Economic Research

Mohrenstr. 58

10117 Berlin

Tel. +49 (30) $89789-0$

Fax +49 (30) $89789-200$

http://www.diw.de

ISSN electronic edition 1619-4535

Papers can be downloaded free of charge from the DIW Berlin website:

http://www.diw.de/discussionpapers

Discussion Papers of DIW Berlin are indexed in RePEc and SSRN:

http://ideas.repec.org/s/diw/diwwpp.html

http://www.ssrn.com/link/DIW-Berlin-German-Inst-Econ-Res.html 


\title{
Energy outlooks compared: Global and regional insights
}

\author{
Dawud Ansari ${ }^{a, b}{ }^{*}$, Franziska Holz ${ }^{a, c}$, Hashem al-Kuhlani ${ }^{a, b}$
}

Dec 12, 2019

\begin{abstract}
a German Institute for Economic Research (DIW Berlin), Mohrenstr. 58, 10117 Berlin, Germany b Energy Access and Development Program (EADP), Wilmersdorfer Str. 122-123, 10627, Berlin, Germany c Norwegian University of Science and Technology (NTNU), Alfred Getz vei 3, 7491 Trondheim, Norway

* Corresponding author: dansari@diw.de
\end{abstract}

\begin{abstract}
:
We compare prominent global energy scenarios of organisations and companies. We supplement the analysis with four own scenarios, which were derived from structured analytic techniques in combination with a numerical global energy and resource market model (Multimod).

Our study provides three central contributions: (i) a compact survey of selected outlooks with meta characteristics (conceptual nature, numerical framework, qualitative elaboration) and quantitative energy system indicators at the global and regional (Europe, Asia-Pacific region, North America) level; (ii) numerous observations from a verbal analysis intended to stimulate future research; and (iii) the discussion of our own outlook.

Among other conclusions, we find that scenarios essentially carrying forward current policies and/or trends lead to future worlds that do not meet the $2^{\circ} \mathrm{C}$ target of the Paris Agreement. Interestingly, there are both normative and exploratory scenarios reaching the Paris Agreement, and there is no consensus between outlooks on how to attain low-emission futures towards 2050. Some scenarios rely on a very strong role of renewables, others on a substantial role of negative emission technologies with fossil fuel use, yet others on assuming decreasing energy demand. There is a strong variation between outlooks with respect to transparency on scenario generation, modelling approach, and data. We argue that, in addition to transparency, the actual inclusion of a qualitative analysis of drivers and storylines helps ensure the political, social and technological feasibility of scenarios.
\end{abstract}

\section{Keywords:}

Energy outlooks; Scenarios; Energy modelling; Climate change; Survey

JEL: Q40, Q47, Q54, C60

We thank Hasan Basri Tosun, Oliver Gnad, Nathan Appleman, Ezaldeen Aref, Ruud Egging, Christian Hauenstein, Sauleh Siddiqui, Christian von Hirschhausen, Claudia Kemfert, and three anonymous reviewers for their helpful comments on earlier versions of the manuscript. We are indebted to the participants of the DIW Berlin Scenario Foresight Workshop in November 2016 and the TU Berlin Scenario Workshop in April 2018. All remaining errors are ours.

This research has received funding from the European Union's Horizon 2020 research and innovation programme under grant agreement no. 691843 (SET-Nav) and the German Federal Ministry of Education and Research's research program Economics of Climate Change II, grant agreement no. 01LA1811B (FoReSee). The authors declare that there is no conflict of interest. 


\section{Introduction}

The first use of scenarios in energy is attributed to Royal Dutch Shell in the late 1960s, using a technique now known as "scenario planning": Planners' analyses of the global business environment prepared Shell's management for the eventuality - if not the timing —of the 1973 oil crisis (Wack, 1985). The original raison d'être of scenario planning, therefore, has been to help decision-makers open their minds to improbable future developments contingent on previously inconceivable or imperceptible' change (Wilkinson and Kupers, 2013).

Scenarios have come a long way from there, fighting their way into the very core of mainstream energy analysis. Several institutions, among them supranational bodies but also civil society organisations and private companies, prepare such studies of the global energy system (often labelled 'outlooks'1). They provide the basis for business and policy decisions. In recent years, scenarios also gained prominence in outlining possible paths to low-carbon futures and for monitoring the status of decarbonisation and climate change (Söderholm et al., 2011). However, as recent studies suggest, the communication, interpretation, and impact of energy scenarios may differ substantially from modellers' intentions (Braunreiter and Blumer, 2018; lyer and Edmonds, 2018). Even more, scenarios can become self-fulfilling prophecies and create the world they were predicting by affecting policy and investment. Carrington and Stephenson (2018), for instance, argue that the International Energy Agency's (IEA) repeated underestimations of solar energy expansion may have hurt the energy transition, which is a topic of discussion though (Metayer et al., 2015).

Given the broad diversity of scenarios alongside their high impact, this article investigates prominent energy outlooks from the IEA, the World Energy Council (WEC), Royal Dutch Shell, Equinor, BP, ExxonMobil, the Massachusetts Institute of Technology (MIT), and the Energy Watch Group / LUT University (EWG/LUT). We complement this panel with our own recent energy outlook (DIW-REM, Ansari et al., 2019), which was generated in a combination of structured analytic techniques and numerical modelling (Ansari and Holz, 2019).

Our study provides three central contributions. First, we provide a compact survey of the outlooks, which helps practitioners and readers to gain an overview of similarities and differences. In this regard, we provide tables and graphs with meta information and quantitative energy system indicators on the global and the regional level (Europe, North America, Asia-Pacific). Second, we provide a verbal analysis of the outlooks and collect observations that shall stimulate future research. Third, we elaborate on our DIW-REM outlook by comparing it to other (mostly incumbent) outlooks.

Comparing numbers between outlooks is not trivial. Differences in accounting, data sources and methods lead to considerable differences between outlooks. We, therefore, attempt to provide an extensive overview and comparison of outlooks in order to bring more transparency and soundness into the debate on scenarios and future energy system trajectories. Our study complements earlier surveys of scenarios and outlooks. The contribution most closely related to ours is Dagnachew et al. (2019), who also review and compare energy outlooks (Shell, BP, IEA, IRENA, WEC, EC, IPCC). However, their analysis only includes scenarios that meet the $2^{\circ} \mathrm{C}$ target. Krey (2014) features a broad comparison of famous energy scenarios in the context of climate change mitigation, and Paltsev (2017) investigates which value the different scenarios add to decision-making. However, both studies eventually focus more on modelling approaches and scenario categorisation than on the numbers. Lund et al. (2017) and Subramanian et al. (2018) are two recent surveys that unfold entirely around providing categories for modelling approaches, going beyond scenarios. Moreover, some regional surveys of scenarios can be found, e.g. for the U.S. (Silberglitt et al., 2003), Denmark (Kwon and Østergaard, 2012), and Brazil (Lucena et al., 2016). Cochran et al. (2014) review both global and regional scenarios with high shares of renewables. Renewable futures are also at the core of other scenario reviews, such as Deason (2018) and Martinot et al. (2007). Furthermore, Weber et al. (2018) analyse decarbonisation futures, and Child et al. (2018) show that existing

\footnotetext{
1 To avoid confusion, we shall use 'outlook' to describe a set of scenarios that are published by the same institution or scenario generation exercise; and we shall use 'scenario' to describe a particular future. In other words, an institution's outlook consists of one or multiple scenarios.
} 
scenarios fail to produce "sustainable" futures. Lastly, there are also scenario comparisons that focus on specific sectors, such as oil (Sorrell et al., 2010) and hydrogen (Quarton et al., 2020).

The remainder of this paper proceeds as follows: First, we give a brief account of the idea of scenarios and the nuances between different types. Then, we present and compare key characteristics of the different energy outlooks on a global level, before proceeding to the regional level. We then discuss our observations before providing some take-away messages for researchers and decision-makers.

\section{A primer on scenarios}

Van Notten (2005, p. 7) defines scenarios as "consistent and coherent descriptions of alternative hypothetical futures that reflect different perspectives on past, present, and future developments, which can serve as a basis for action". They differ from other methods mainly in the type of questions. While contingency planning focuses on 'what if?' questions by presenting a base case and an exception (or contingency), "scenarios explore the joint impact of various uncertainties which stand side by side as equals" (Schoemaker, 1995, p. 26). Scenario building also differs from sensitivity analysis with regards to how uncertainty is approached. While the former generally considers simultaneous modifications of several variables, sensitivity analysis only focuses on the effect of modifying one variable while keeping everything else unchanged.

First, scenarios must be distinguished from forecasting methods and other prediction-oriented techniques. The latter seek to predict the future with utmost accuracy, whereas the "strength of scenarios is that they do not describe just one future, but that several realisable or desirable futures are placed side by side." (Mietzner and Reger, 2005, p. 235). In this context, and opposed to forecasting, the term "plausibility" is more central than "probability" (Derbyshire, 2017). Scenarios, hence, explore the range of plausible futures rather than necessarily aiming at finding the most probable of them.

Moreover, there is a seemingly small, yet important, distinction between scenario building and scenario planning. As summarised by Mietzner and Reger (2005, p. 223), "building scenarios means speculating about the uncertainty surrounding the future", while scenario planning is "a management technology used by managers to articulate their mental models about the future and thereby make better decisions" and thereby relies on the former as its foundation.

Ultimately, scenario building exercises rely on a smart balance between qualitative and quantitative information inputs that can tell "a story of how various elements might interact under uncertain conditions" (Schoemaker, 1995, p. 26). Nevertheless, the actual way of handling both inputs varies considerably and may range from thorough methods for including a multitude of drivers to the use of numerical models to combinations of them. In this sense, drivers can be understood as the qualitative equivalent to numerical (input) variables; they are "important factors that will decide the nature of the future environment" (Mercer, 1995, p. 83) and the typical foundation of the scenario analysis.

Often, several scenarios are developed by the same institution at the same time, with the desire to englobe a large plausible range of potential futures. As the uncertainty and, hence, the spread between scenarios) increases over time., the entire range of potential futures is often referred to as the 'scenario cone' (e.g. Amer et al., 2013). The outermost limits of this cone (see Figure 1) are scenarios that are objectively impossible, followed by futures that are possible but not necessarily

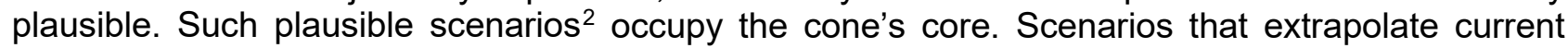
trends most closely are usually called 'probable' scenarios (Godet and Roubelat, 1996), whereas (un-)preferable scenarios can be found at the core's boundaries. We typically refer to them as "best" ("worst") cases. Lastly, a wild card is the "description of an occurrence that is assumed to be improbable, but which would have large and immediate consequences" (Mendonça et al., 2004, p. 201) on the future trajectory.

\footnotetext{
2 The eventual meaning of 'plausibility' is controversial (see Ramírez and Selin, 2014; Wiek et al., 2013), but a possible
} definition is "the quality of a scenario to hold enough evidence to be qualified as 'occurrable"' (ibid. , p. 138). 
Scenarios can be categorised in various ways (see e.g. Krey, 2014; Lund et al., 2017; Subramanian et al., 2018). When looking at climate scenarios, a particularly interesting dimension is whether scenarios are exploratory (i.e. what will happen in a specific setting) or normative (i.e. what should happen). Both are entirely different ways to approach scenarios: Exploratory scenarios start in the present and analyse how the future evolves given certain conditions and assumptions. Normative scenarios (sometimes labelled target scenarios) are futures that are constructed deliberately to reach a certain final state, for example an emissions target. In the climate debate, for instance, an exploratory scenario could analyse which emissions will occur towards 2050 if a certain policy is adopted, while a normative one could assume (target) a carbon-free 2050 and analyse a pathway from today to that 2050 world.

Many of the outlooks discussed in this article contain "best cases" and "worst cases", for which the line between explorative and normative is blurry. Their deliberate aim is to illustrate (un-)preferable futures. Yet, they are explorative in nature as long as they were generated based on (present) drivers (as opposed to pre-defining a final target).

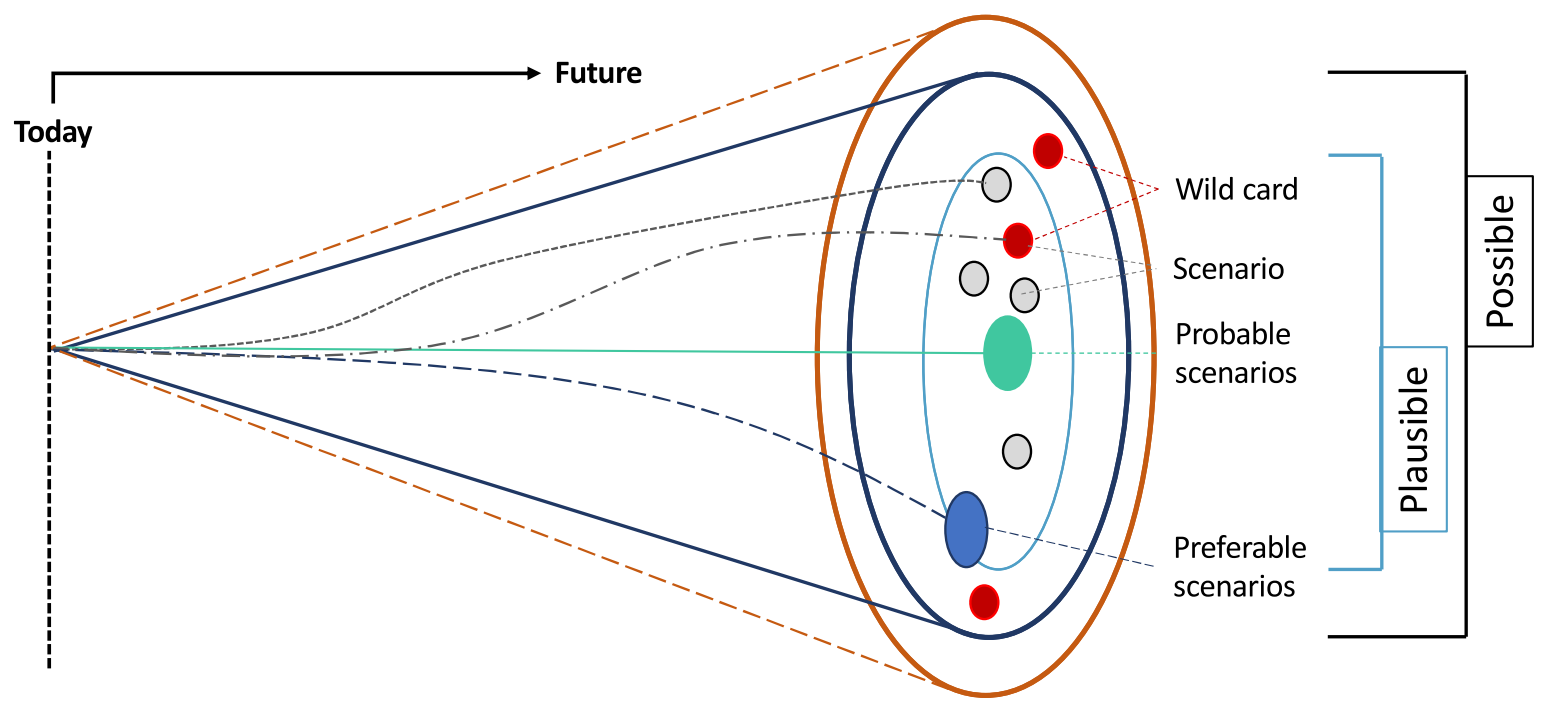

Figure 1: Illustration of the scenario cone

\section{A world of scenarios}

In this section, we present the results of our survey with respect to meta information of the different outlooks. We start with an introduction into the setting of the study before detailing the different outlook characteristics that we surveyed and introducing the individual outlooks.

For this study, we consider prominent scenarios with different characteristics and methods. First, we consider the World Energy Outlook (WEO), which is published by the International Energy Agency (IEA) - an intergovernmental, public body established in the framework of the OECD - and arguably the most prominent energy outlook. We also consider the energy outlooks published by the World Energy Council (WEC), a global energy body with UN accreditation; the international oil companies Royal Dutch Shell, BP, Equinor, and ExxonMobil; as well as the research institution MIT; and the scientist-led civil society organisation Energy Watch Group (in cooperation with LUT University). Moreover, we add our own recent energy outlook to the comparison: four scenarios that are the result of research at the Resource and Environmental Market division at the German Institute for Economic Research DIW Berlin (DIW-REM).

All outlooks deal with the entire energy system on the supply and the demand side, including the ones by the major oil companies. They are, hence, more comprehensive than sectoral scenario analyses for only the natural gas sector or only the oil sector such as in Holz et al. (2015) or Ansari (2017). Our precise choice of outlooks is motivated as follows: First, we aim at including outlooks that are recognised strongly by both an academic and a non-academic audience. Secondly, we target examples for the different kinds of actors that create scenarios (a government agency, private 
energy companies, research institutions, and civil society). Moreover, limiting the scope of the survey to nine outlooks allows us to present detailed remarks with regards to the individual outlooks. At the same time, we want to present the existing variety of potential trajectories and do not limit our analysis to $2^{\circ} \mathrm{C}$ scenarios as Dagnachew et al. (2019).

Each outlook was developed in a different context - and this context will be reflected in the choice of scenarios, their assumptions, as well as in the qualitative nature of the outlook (see below). For example, some energy companies use a scenario foresight process to gain a deep understanding of the uncertainties in their business environment (see Wack, 1985). Other scenarios were designed to show pathways to certain climate or energy targets (e.g. renewable shares or emissions), and others again depict worlds of continued conventional and fossil fuel consumption. In general, the selected energy outlooks often contain several scenarios in order to display and explore the uncertainty of future energy system developments.

We survey and compare each outlook regarding a general description of the scenario, its climate change mitigation performance, its computational modelling approach, its nature, and its qualitative depth. Table 1 provides an overview of the results. Somewhat complementary to our overview in this chapter, we also refer to Dagnachew et al. (2019) for a summary of scenario drivers, characteristics, and assumptions of some selected $2^{\circ} \mathrm{C}$ scenarios.

First, we assess the degree of climate change mitigation in terms of the scenarios' ability to meet the Paris Agreement (i.e. whether cumulative emissions are sufficiently low to prevent $2^{\circ} \mathrm{C}$ global warming as self-reported by each outlook) as well as the annual $\mathrm{CO}_{2}$ emissions in 2050. Moreover, we assess the numerical framework and the scenarios' nature (i.e. whether it is exploratory or normative). We use publicly available information on the scenarios and their respective planning processes as given in their publications (IEA 2018, Shell 2013, WEC 2016, Equinor 2018, BP 2019, Ansari et al. 2019, Reilly et al. 2018, ExxonMobil 2018, Ram et al. 2019). Lastly, Table 1 rates each scenario's qualitative elaboration, i.e. whether the scenario contains a solid storyline resulting from a detailed analysis of drivers. Our ranking is divided into:

- Strong: The scenario is based on a set of drivers, it features a detailed verbal storyline of the events between the start and the final state of the scenario, and it considers social, political, technical, and economic factors alike.

- Moderate: The scenario features a verbal storyline, but it lacks an elaboration of the underlying drivers or fails to elaborate on any of the dimensions mentioned above.

- Weak: The scenario's verbal storyline focusses on single aspects only or does not exist at all.

The IEA (2018b) World Energy Outlook contains three scenarios: "Current Policies" and "New Policies", which assume a world with current and recently announced energy and climate policies, respectively, and "Sustainable Development", which assesses the pathway to universal energy access and climate change mitigation. The first two scenarios are exploratory simulations with the World Energy Model that result in low climate change mitigation, while the latter is a normative assessment that is designed to meet the Sustainable Development Goals in a cost-minimising way (see IEA (2018a) for the model description). Neither of the scenarios has a real storyline besides these brief descriptions. Noticeably, Current Policies has the lowest share of renewable electricity of all scenarios analysed in this study.

Shell's scenarios - Shell (2013)'s "Ocean" and "Mountain" and Shell (2018)'s "Sky" -, in contrast, have dedicated storylines that feature detailed events and timelines on both global and regional levels. While Sky is a normative assessment designed to meet climate goals, Ocean and Mountain are exploratory assessments of energy systems that result from drivers that are largely connected to economic governance. In accordance, numbers are computed in a simulation.

The WEC (2016) outlook contains three scenarios, which can arguably be understood as best ("Unfinished Symphony"), base ("Modern Jazz"), and worst case ("Hard Rock"). The scenarios are the result of an iterative process between qualitative development (based on expert interviews and scenario framing workshops) and the Global Multi-Regional MARKAL model. All scenarios are 
Table 1: Overview of prominent energy outlooks

\begin{tabular}{|c|c|c|c|c|c|c|c|}
\hline Institution & $\begin{array}{l}\text { Scenario and } \\
\text { version }\end{array}$ & Description & $\begin{array}{l}\text { Paris } \\
\text { Agreement } \\
\text { met?* }\end{array}$ & $\begin{array}{l}\mathrm{CO}_{2} \\
\text { emissions } \\
\text { in } 2050 \\
\text { (Gt) }\end{array}$ & $\begin{array}{l}\text { Modelling } \\
\text { framework }\end{array}$ & $\begin{array}{l}\text { Scenario } \\
\text { nature }\end{array}$ & $\begin{array}{l}\text { Elaboration } \\
\text { on drivers } \\
\text { and } \\
\text { storylines }\end{array}$ \\
\hline \multirow{3}{*}{ IEA } & $\begin{array}{l}\text { New Polices } \\
(2018)\end{array}$ & $\begin{array}{l}\text { Policies adopted and announced } \\
\text { until mid-2018 }\end{array}$ & no & $33.9^{\star}$ & \multirow{2}{*}{$\begin{array}{l}\text { Iterative, multi- } \\
\text { step simulation } \\
\text { with logit fuel } \\
\text { switch and cost } \\
\text { minimisation } \\
\text { models }\end{array}$} & exploratory & \multirow{3}{*}{ weak } \\
\hline & $\begin{array}{l}\text { Current } \\
\text { Policies (2018) }\end{array}$ & Policies adopted until mid-2018 & no & $42.5^{\star}$ & & exploratory & \\
\hline & $\begin{array}{l}\text { Sustainable } \\
\text { Development } \\
\text { (2018) }\end{array}$ & $\begin{array}{l}\text { Measures necessary to achieve } \\
\text { energy-related SDGs }\end{array}$ & yes & $17.7^{\star}$ & $\begin{array}{l}\text { Cost minimisation } \\
\text { including the } \\
\text { simulation }\end{array}$ & normative & \\
\hline \multirow{3}{*}{ Shell } & Sky (2018) & $\begin{array}{l}\text { Paris-compliant pathway with zero } \\
\text { net-emissions by } 2070\end{array}$ & yes & 18.5 & \multirow{3}{*}{$\begin{array}{l}\text { Iterative, multi- } \\
\text { step simulation } \\
\text { with multinomial } \\
\text { logit energy } \\
\text { choice and energy } \\
\text { ladders }\end{array}$} & normative & \multirow{3}{*}{ strong } \\
\hline & Ocean (2013) & $\begin{array}{l}\text { Dynamic world with fast economic } \\
\text { pace and pressure on resources }\end{array}$ & $\mathrm{no}^{+}$ & 40.0 & & exploratory & \\
\hline & $\begin{array}{l}\text { Mountain } \\
(2013)\end{array}$ & $\begin{array}{l}\text { Incumbent-driven top-down world } \\
\text { with economic stagnation }\end{array}$ & $\mathrm{no}^{+}$ & 28.0 & & exploratory & \\
\hline \multirow[t]{2}{*}{ WEC } & $\begin{array}{l}\text { Unfinished } \\
\text { Symphony } \\
(2016)\end{array}$ & $\begin{array}{l}\text { United top-down push for stringent } \\
\text { regulations consolidates markets } \\
\text { and enables sustainability }\end{array}$ & no ${ }^{+}$ & 18.1 & \multirow{2}{*}{$\begin{array}{l}\text { Cost minimisation } \\
(\mathrm{LP})\end{array}$} & $\begin{array}{l}\text { exploratory } \\
\text { (best case) }\end{array}$ & \multirow[t]{2}{*}{ strong } \\
\hline & $\begin{array}{l}\text { Modern Jazz } \\
(2016)\end{array}$ & $\begin{array}{l}\text { Innovation-driven world shaped by } \\
\text { market mechanisms and fast } \\
\text { economic growth }\end{array}$ & no & 29.7 & & exploratory & \\
\hline
\end{tabular}




\begin{tabular}{|c|c|c|c|c|c|c|c|}
\hline & $\begin{array}{l}\text { Hard Rock } \\
(2016)\end{array}$ & $\begin{array}{l}\text { Geopolitical tensions nationalise } \\
\text { policy and paralyse economy and } \\
\text { transition }\end{array}$ & no & 35.7 & & $\begin{array}{l}\text { exploratory } \\
\text { (worst case) }\end{array}$ & \\
\hline \multirow{3}{*}{ Equinor } & $\begin{array}{l}\text { Renewal } \\
(2019)\end{array}$ & $\begin{array}{l}\text { Global convergence enables } \\
\text { progressiveness and inclusiveness } \\
\text { with strong climate policies }\end{array}$ & yes & 10.6 & \multirow{3}{*}{$\begin{array}{l}\text { No information } \\
\text { given }\end{array}$} & $\begin{array}{l}\text { exploratory } \\
\text { (best case) }\end{array}$ & \multirow{3}{*}{ moderate } \\
\hline & Reform (2019) & $\begin{array}{l}\text { Ambivalent world continues current } \\
\text { trends }\end{array}$ & no & 29.0 & & exploratory & \\
\hline & Rivalry (2019) & $\begin{array}{l}\text { Escalating geopolitical situation } \\
\text { depresses the global economy but } \\
\text { increases energy growth drastically }\end{array}$ & no & 35.9 & & $\begin{array}{l}\text { exploratory } \\
\text { (worst case) }\end{array}$ & \\
\hline \multirow{4}{*}{ BP } & $\begin{array}{l}\text { Evolving } \\
\text { Transition } \\
\text { (2019) }\end{array}$ & $\begin{array}{l}\text { Current trends are extrapolated into } \\
\text { the future }\end{array}$ & no & 35.9 & \multirow{4}{*}{$\begin{array}{l}\text { No information } \\
\text { given }\end{array}$} & exploratory & \multirow{4}{*}{ weak } \\
\hline & $\begin{array}{l}\text { Rapid } \\
\text { Transition } \\
\text { (2019) }\end{array}$ & Low-carbon policies in all sectors & $\mathrm{no}^{+}$ & $18.0^{4}$ & & exploratory & \\
\hline & $\begin{array}{l}\text { More Energy } \\
(2019)\end{array}$ & $\begin{array}{l}\text { Strong increase of energy demand } \\
\text { from emerging economies }\end{array}$ & no & $\mathrm{N} / \mathrm{A}$ & & exploratory & \\
\hline & $\begin{array}{l}\text { Less } \\
\text { Globalisation } \\
\text { (2019) }\end{array}$ & $\begin{array}{l}\text { Trade disputes create energy } \\
\text { security concerns and a slowdown } \\
\text { of the global economy }\end{array}$ & no & $N / A$ & & exploratory & \\
\hline DIW-REM & $\begin{array}{l}\text { Business as } \\
\text { Usual (2019) }\end{array}$ & $\begin{array}{l}\text { Continuation of current trends with } \\
\text { delayed and insufficient } \\
\text { decarbonisation due to conflicting } \\
\text { interests }\end{array}$ & no & $28.2^{\nabla}$ & $\begin{array}{l}\text { Partial equilibrium } \\
\text { (MCP / QCP) }\end{array}$ & exploratory & strong \\
\hline
\end{tabular}




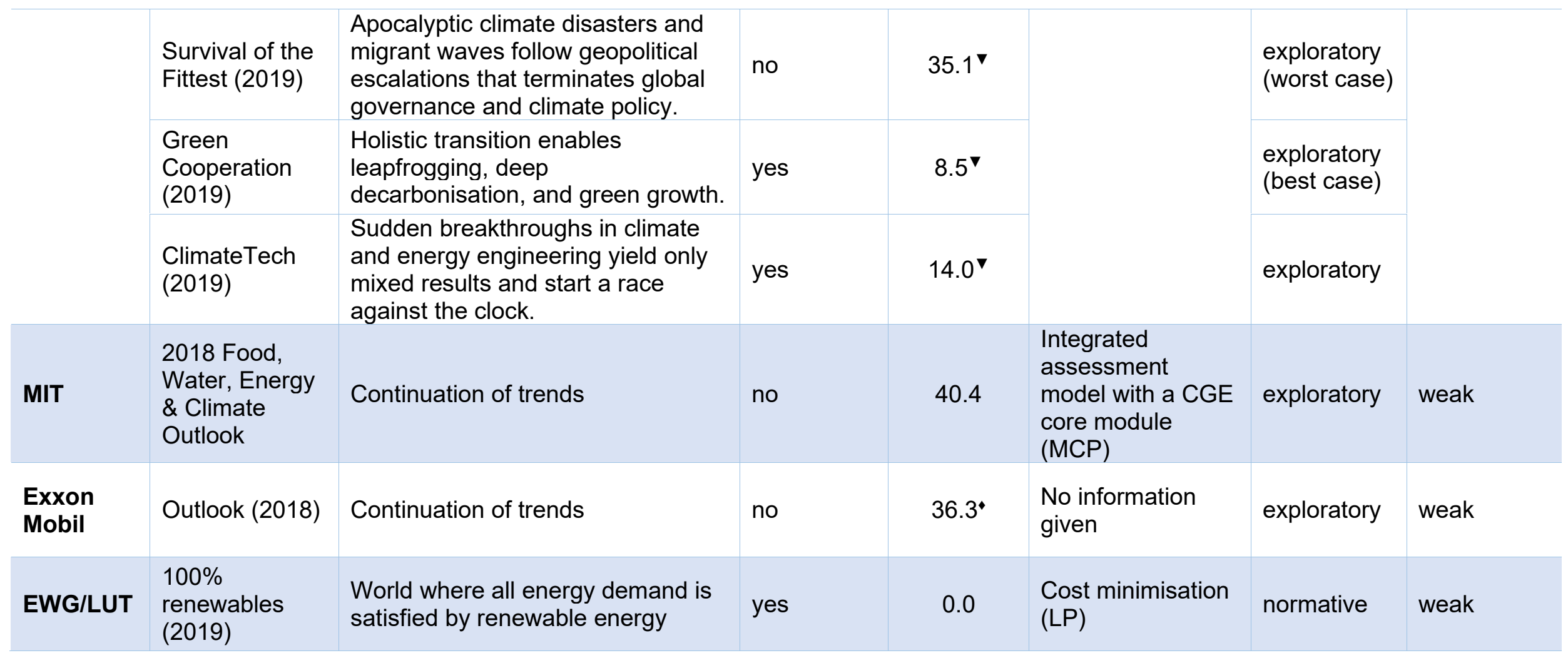

* Below $1000 \mathrm{Gt}$ cumulative $\mathrm{CO}_{2}$ emissions until 2050

+ Emissions consistent with a $2^{\circ} \mathrm{C}$ goal are reached in a later year than 2050

- Numbers for 2040 (final scenario year)

v Numbers for 2055 (final scenario year) 
exploratory analyses - that are essentially carrying forward current policies and/or trends - which is why even the best-case does not meet climate goals by 2050 (only by 2060).

The Equinor (2019) outlook has a very similar setup (best case "Renewal", business-as-usual "Reform", and worst case "Rivalry") and considers three worlds of global (non-)cooperation reflected in the energy system. Despite the similarities to the two previous outlooks, the degree of storyline sophistication is weaker than in the case of WEC or Shell and does not feature detailed events, timelines, and storylines which reflects the smaller scenario planning process that is internal to the organisation. Their best case meets the climate goals, while base and worst case fail to do so.

The BP (2019) outlook features a business-as-usual projection ("Evolving Transition"), similar to the definition of the IEA WEO's Current Policies Scenario, and a number of scenarios that consider slight variations: stricter climate policies ("Rapid Transition"), a positive shock on energy demand ("More Energy"), and the case of decreasing global trade and GDP ("Less Globalization"). The outlook lacks a foundation with transparent drivers.

The setup and method of our DIW-REM Outlook (Ansari et al., 2019) is similar (but not equal) to the WEC outlook (see Ansari and Holz, 2019). It was developed in an iterative combination of structured analytic techniques (Burrows and Gnad, 2018; Heuer and Pherson, 2015) and the numerical energy and resource market model Multimod (Huppmann and Egging, 2014). The latter represents the energy system by a game-theoretic equilibrium which includes market power by some players and is implemented as a mixed complementarity problem. The scenarios "Business as Usual", "Survival of the Fittest", "Green Cooperation", and "ClimateTech" represent the base, the best, the worst, and the surprise case, respectively. Noticeably, all four scenarios display very high levels of renewable electricity generation, although only the best and the surprise case are able to meet the Paris Agreement climate goals. Moreover, the worst case ends in a near-apocalyptic climate catastrophe, which is why most numbers towards 2050 show sharp decreases in this scenario.

The remaining three examples are no outlooks in the previous sense of a line-up of futures, but each one contains one scenario only. The MIT scenario "Food, Water, Energy \& Climate Outlook" (Reilly et al., 2018) which uses an integrated assessment model (see Sokolov et al., 2005), and the ExxonMobil (2018) outlook consider a continuation of current trends. The two outlooks are remarkably similar: Neither of them reports a well-founded storyline or meets ambitious climate targets. Moreover, the levels of emissions and renewable electricity generation towards 2050 are very similar. On the contrary, the EWG/LUT scenario (Ram et al., 2019) is a normative scenario that assesses the pathway to a $100 \%$ renewable energy system as a minimisation of total system costs. Yet, this outlook does not contain a qualitative description either.

\section{Global insights}

This section presents and compares energy system indicators for the global level in the different outlooks. Table 1 visualises global trajectories of several indicators in the different scenarios. Its three panels show the trajectories of total primary energy demand, total coal demand, and electricity generation. Different scenarios of the same outlook share common marker symbols, while scenarios within outlooks are distinguished by different colours. The latter indicate the annual $\mathrm{CO}_{2}$ emissions in the final outlook year ${ }^{3}$, ranging from green (low $\mathrm{CO}_{2}$ emissions) to red (high $\mathrm{CO}_{2}$ emissions). Typically, an outlook will have one green trajectory (its "best case"), one red trajectory ("worst case"), and one orange trajectory (for example, of its Business-as-Usual case). Table 2 complements the trajectories by depicting different fuel shares towards 2050.

Global total primary energy demand shows considerable variation between the scenarios but also some common characteristics. All scenarios witness major energy demand increases in the 2030s apart from IEA Sustainable Development and Equinor's Renewal. The latter is an outlier and even exhibits declining demand, which else is found only in WEC's Unfinished Symphony. There is no apparent common pattern towards 2050: Energy demand projections cover a wide range of possible developments, regardless of the type of scenario. Shell scenarios project the highest growth in

\footnotetext{
${ }^{3}$ Some outlooks report emissions only for years earlier or later than 2050, e.g., 2040 or 2060.
} 
demand that is only seconded by our Green Cooperation and ClimateTech scenarios. Our Survival of the Fittest scenario is the only one to foresee climate catastrophes as early as in the 2040s which diminishes human activity in some world regions and, hence, decreasing aggregated energy demand. Another special and distinct case is EWG/LUT, which operates on another level and starts off approximately one-third below all other scenarios in 2015. However, eventually all outlooks exhibit somewhat different levels for the (sometimes even identical) base year. Accounting differences likely explain this fact, since the base year is a past observation and no model outcome.
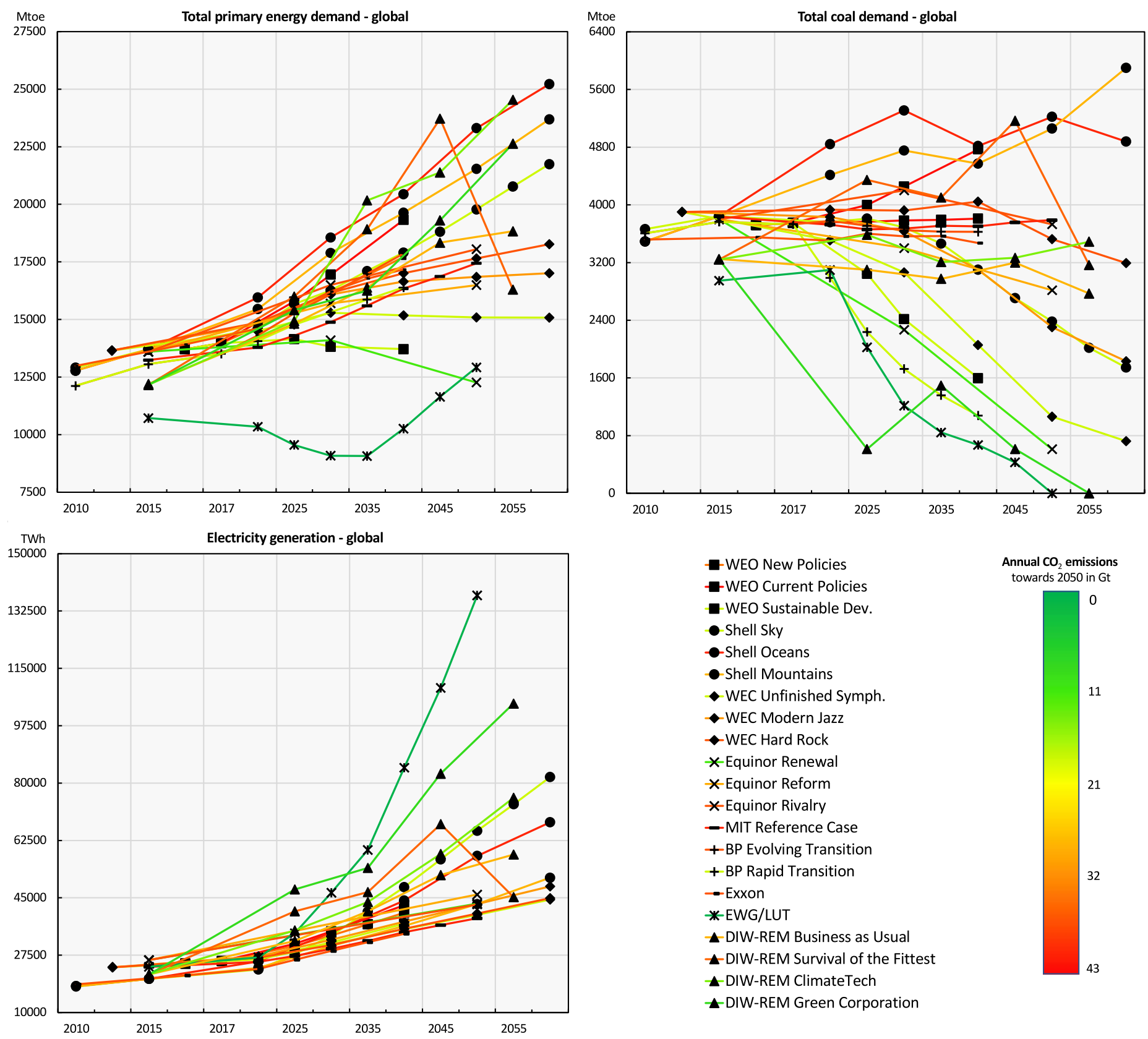

-WEO New Policies
-WEO Current Policies
- WEO Sustainable Dev.
- Shell Sky
- Shell Oceans
- Shell Mountains
- WEC Unfinished Symph.
- WEC Modern Jazz
- WEC Hard Rock
-Equinor Renewal
-Equinor Reform
-Equinor Rivalry
- MIT Reference Case
+-BP Evolving Transition
+-BP Rapid Transition
- Exxon
*-EWG/LUT
-DIW-REM Business as Usual
- DIW-REM Survival of the Fittest
—-DIW-REM ClimateTech
—-DIW-REM Green Corporation

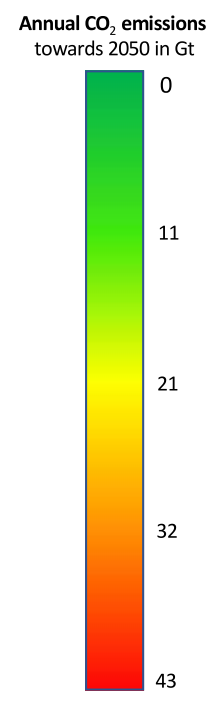

Figure 2: Global total primary energy demand, coal demand, and electricity generation compared.Note: The colours of the lines reflect the annual $\mathrm{CO}_{2}$ emissions level in the final outlook year (in $\mathrm{Gt} \mathrm{CO}_{2}$ ); DIW-REM electricity generation is adjusted to a common base year level

Total global coal demand projections diverge along the lines of scenario types. Best-case scenarios all include significant drops in global coal demand (most notably BP's Evolving Transition, DIW's Green Cooperation, and EWG/LUT), starting as early as 2020 and approaching zero towards 2050. The latecomer in this category is Shell's Sky, which begins to drop only by 2040. Most base-case scenarios (ExxonMobil, MIT, Equinor, BP, DIW-REM) consider stagnating or slowly decreasing coal demand, and the group of worst-case scenarios includes both stagnating and even increasing coal 
demand. There are, however, two major exceptions to this pattern: First, Shell's Oceans and Mountains scenarios present severe increases in coal demand. Second, WEC's Unfinished Symphony mimics the trajectories of the best cases rather than that of other business-as-usual cases.

Regarding global electricity generation, finally, all scenarios (except our DIW-REM Green Cooperation path) start on a common trajectory of moderate electricity growth towards 2020, followed by steeper growth towards 2030. Around 2040, the scenarios start to diverge: The EWG/LUT scenario considers an unprecedented and severe electrification boom, which exceeds a sevenfold increase between 2020 and 2050. Not far from that is our DIW-REM Green Cooperation scenario, whose 2055 number amounts to a fivefold increase from 2020. The remaining variation between scenarios, however, shows no pattern concerning institutions or scenario type.

Table 2: Fuel shares in primary energy demand in 2050

\begin{tabular}{|c|c|c|c|c|c|}
\hline Institution & Scenario & $\begin{array}{c}\text { Coal } \\
(\%)\end{array}$ & $\begin{array}{l}\text { Gas } \\
(\%)\end{array}$ & $\begin{array}{l}\text { Oil } \\
(\%)\end{array}$ & $\begin{array}{c}\text { Renewables } \\
(\%)\end{array}$ \\
\hline \multirow[t]{3}{*}{ IEA * } & New Polices (2018) & 21.5 & 25.0 & 27.6 & 20.3 \\
\hline & Current Policies (2018) & 24.7 & 24.9 & 28.8 & 8.9 \\
\hline & Sustainable Development (2018) & 11.6 & 23.0 & 25.0 & 30.9 \\
\hline \multirow[t]{3}{*}{ Shell } & Sky (2018) & 12.1 & 13.9 & 19.3 & 45.8 \\
\hline & Ocean (2013) & 22.4 & 19.0 & 22.6 & 30.6 \\
\hline & Mountain (2013) & 23.5 & 26.3 & 17.8 & 22.1 \\
\hline \multirow[t]{3}{*}{ WEC } & Unfinished Symphony (2016) & 7.0 & 25.3 & 25.56 & 30.9 \\
\hline & Modern Jazz (2016) & 13.7 & 29.5 & 27.0 & 23.4 \\
\hline & Hard Rock (2016) & 20.0 & 24.0 & 29.3 & 18.9 \\
\hline \multirow[t]{3}{*}{ Equinor } & Renewal (2019) & 5.0 & 21.56 & 19.1 & 44.0 \\
\hline & Reform (2019) & 17.1 & 24.1 & 26.1 & 26.8 \\
\hline & Rivalry (2019) & 20.7 & 22.1 & 30.3 & 22.0 \\
\hline \multirow[t]{2}{*}{$B P * \nabla$} & Evolving Transition (2019) & 20.3 & 25.8 & 27.2 & 22.3 \\
\hline & Rapid Transition (2019) & 6.0 & 24.3 & 21.5 & 34.2 \\
\hline \multirow{4}{*}{$\begin{array}{l}\text { DIW-REM } \\
+\end{array}$} & Business as Usual (2019) & 13.9 & 19.5 & 22.8 & 41.3 \\
\hline & Survival of the Fittest (2019) & 19.4 & 39.3 & 19.3 & 20.7 \\
\hline & Green Cooperation (2019) & 0.00 & 12.1 & 2.1 & 84.6 \\
\hline & ClimateTech (2019) & 14.2 & 22.6 & 15.0 & 31.0 \\
\hline MIT & $\begin{array}{l}2018 \text { Food, Water, Energy \& } \\
\text { Climate Outlook }\end{array}$ & 21.7 & 23.9 & 33.0 & 18.7 \\
\hline $\begin{array}{l}\text { Exxon } \\
\text { Mobil* }\end{array}$ & Outlook (2018) & 20.3 & 25.7 & 31.0 & 16.5 \\
\hline EWG/LUT & $100 \%$ renewables (2019) & 0 & 0 & 0 & 100 \\
\hline
\end{tabular}


Figures for the share of renewable energy differ considerably between outlooks and scenarios (Table 2). Towards 2050, IEA's Current Policies exhibits the lowest share of renewables (9\%), and EWG/LUT the highest one (100\%). The numbers show stark differences even within the group of climate mitigation scenarios: Besides EWG/LUT, DIW's Green Cooperation is the only scenario with a renewable share above $50 \%$. The best cases Shell Sky and Equinor Renewal but also DIW-REM's Business as Usual have renewable shares around $40 \%$. The other scenarios with substantial $\mathrm{CO}_{2}$ emission reduction achievements (IEA's Sustainable Development, DIW-REM ClimateTech, BP Rapid transitions, and Modern Jazz) exhibit around 30\% renewables in their final outlook year. All other scenarios are located at around $20 \%$ renewable share without any remarkable further patterns.

The share of gas towards 2050 differs far less than that of renewables: Except for EWG/LUT (which considers an energy system without fossil fuels, including natural gas) and DIW's Survival of the Fittest, all scenarios lie in a corridor between $10 \%$ and $30 \%$. Notably, DIW-REM shows the largest spread within one outlook with nearly 30 percentage points. For the other outlooks, the future of gas shows only little variation between scenarios (between 12 percentage points between the Shell scenarios and only 1 percentage point in BP).

\section{Regional insights}

In this section, we present and compare numerical energy system indicators at the regional level. The subsections cover the three largest energy-consuming regions: Europe, Asia-Pacific, and North America. All outlooks focus on the global level, and the quality and extent of their regional analyses differ between them. While some provide comprehensive numbers (e.g. MIT, Shell), other outlooks barely consider the regional level and present only selected numbers (e.g. BP and, slightly more detailed, WEC). For DIW-REM, on which we will put greater emphasis in this section, regional numbers are also available and presented here.

\subsection{Europe}

Europe (Figure 3 ) has committed to a continuously increasing role of renewables and a sizeable reduction of its greenhouse gas emissions, if not decarbonisation. The development of total primary energy demand in Europe seems more driven by outlooks than by scenario types. In other words, towards 2050 , scenario trajectories are very similar within a single outlook instead of showing trends across outlooks based on drivers or scenario types. For instance, at the global level, best cases tend to have similar trajectories. However, for Europe, it seems that the scenarios follow the trends of their outlooks, regardless of whether they are best or worst cases. For example, all DIW-REM scenarios project significant growth in demand, exceeding any other outlook. Especially Green Cooperation foresees a steep increase that exceeds today's levels by twofold, reflecting its vision of green growth. Similarly, all Shell scenarios follow a stagnating to increasing energy demand path, where Mountains comes closest to our scenario results. Furthermore, all Equinor scenarios yield similar results towards 2050. Besides that, the EWG/LUT trajectory for the European Union mimics its global counterpart and foresees a late increase only after 2035. All other scenarios display modest to substantial decreases in energy demand, perhaps reflecting strong efforts in energy efficiency; the most articulate example for this is Equinor's Renewal.

All outlooks show a common trend in European coal consumption, namely the decrease of coal use throughout the next decades. The most ambitious outlook is, again, DIW-REM, with all scenarios witnessing steep decreases in the 2020s. Green Cooperation eventually phases out coal by 2035 , shortly before BP's Rapid Transition. After that, a cloud of best-case scenarios approaches a coal phase out by or before 2050. On the upper end of the range, worst-case scenarios only project a reduction in coal production by approximately one half.

Electricity production offers the largest variety in European energy development forecasts: EWG's renewable outlook and DIW-REM's Green Cooperation project a more-than-fivefold increase in power generation, while the entire IEA outlook considers a stagnation of European electricity generation. The remaining few scenarios that present disaggregated electricity generation numbers are in between these two extremes. 

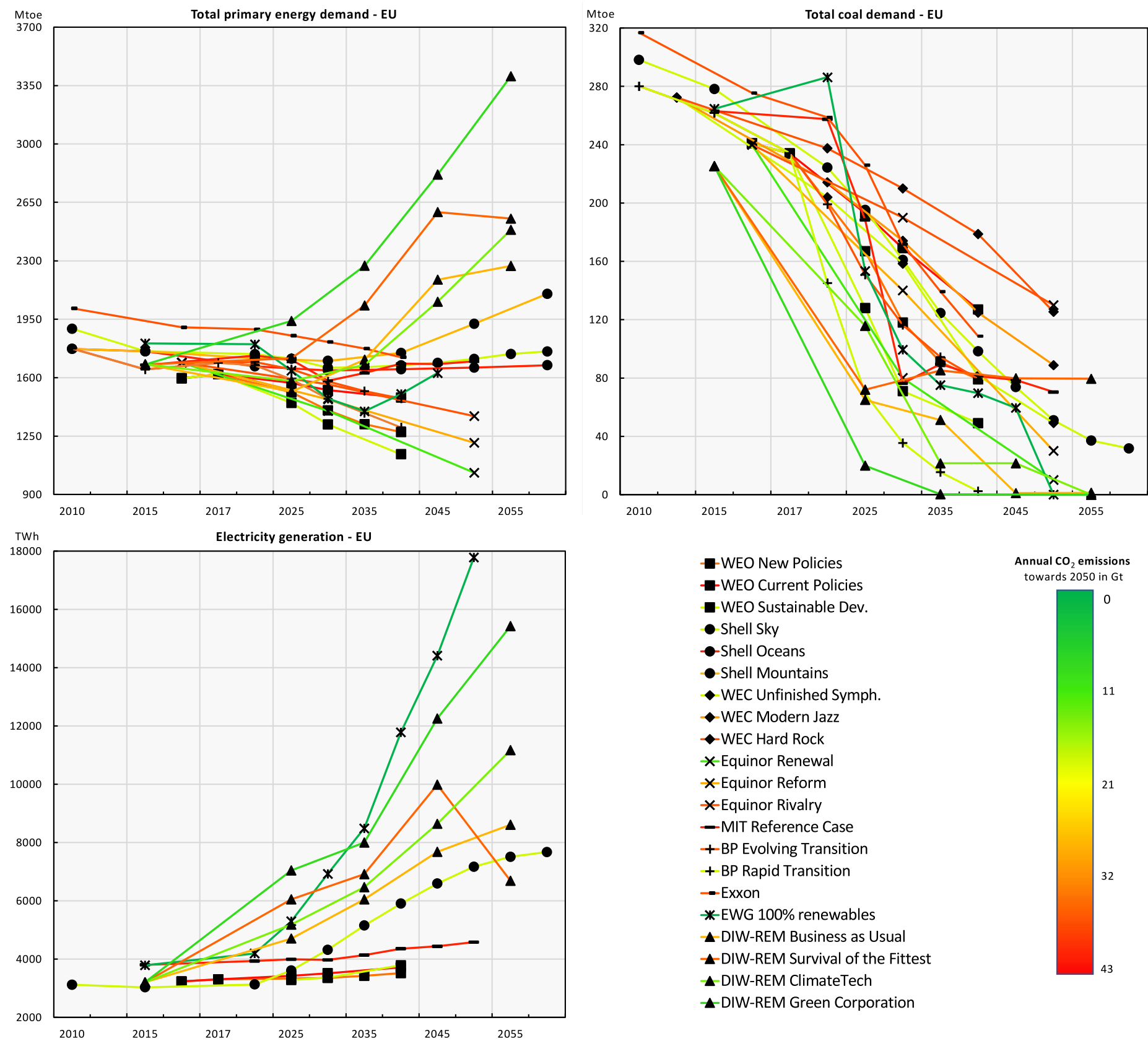

-WEO New Policies

-WEO Current Policies

-WEO Sustainable Dev.

- Shell Sky

- Shell Oceans

- Shell Mountains

- WEC Unfinished Symph.

-WEC Modern Jazz

$\bullet$ WEC Hard Rock

×-Equinor Renewal

$\times$ Equinor Reform

*Equinor Rivalry

-MIT Reference Case

+BP Evolving Transition

+ BP Rapid Transition

-Exxon

*EWG $100 \%$ renewables

$\triangle$ DIW-REM Business as Usual

$\triangle$ DIW-REM Survival of the Fittest

$\Delta$-DIW-REM ClimateTech

^DIW-REM Green Corporation

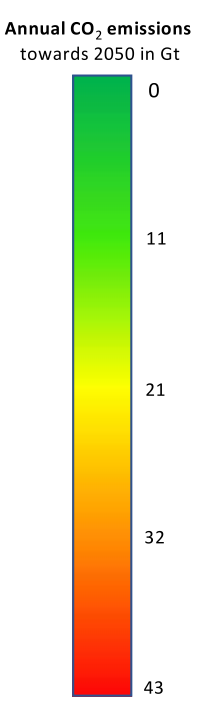

2010

Figure 3: Total primary energy demand, coal demand, and electricity generation in the European Union compared.Notes: The colours of the lines reflect the annual $\mathrm{CO}_{2}$ emissions level in the final outlook year (in $\mathrm{Gt} \mathrm{CO}_{2}$ ); WEC numbers are adjusted to match the regional disaggregation "European Union"; DIW-REM electricity generation level is adjusted to a common base year level

\subsection{Asia-Pacific}

Asia-Pacific (Figure 5) is a very diverse region that groups together extremes ranging from developing countries to high-income countries. While an increase in energy and emission intensity over the next decades is probable, emerging environmental concerns are leading to tougher environmental policies and favour renewables or nuclear energy.

Most scenarios show a strong increase in total primary energy demand in the 2020 s and high-tomoderate increases in the 2030s. A general exception to this is the EWG/LUT outlook, where, again, the regional pattern mimics the global behaviour of an initial drop followed by a late increase. Also, the best cases of IEA and Equinor as well as the DIW-REM business-as-usual case show a stagnation (or even decrease) of energy demand in Asia towards 2040 and beyond, reflecting the decoupling of energy demand growth and economic growth. The highest projection comes from 
Shell's Sky, which exhibits a constant path of demand growth. All other scenarios lie in between these values.

Coal demand in Asia-Pacific shows divergent futures. Both exploratory IEA WEO scenarios show considerable growth in coal demand, while most other base and worst cases consider a stagnation or only moderate increases. All best cases (and some other scenarios with stricter climate policies) hint at a tremendous decrease in coal demand. DIW-REM and EWG/LUT have the fastest phaseout. Shell's Sky, however, only initiates the path towards a phase-out around 2050.

Asian-Pacific electricity generation, finally, shows a homogenous trend of moderate increases in the 2020 s and a more rapid ascent in the 2030s. Towards 2050, however, the spread between scenarios becomes broader again, with EWG/LUT and Green Cooperation at the upper end and the MIT outlook on the lower one.
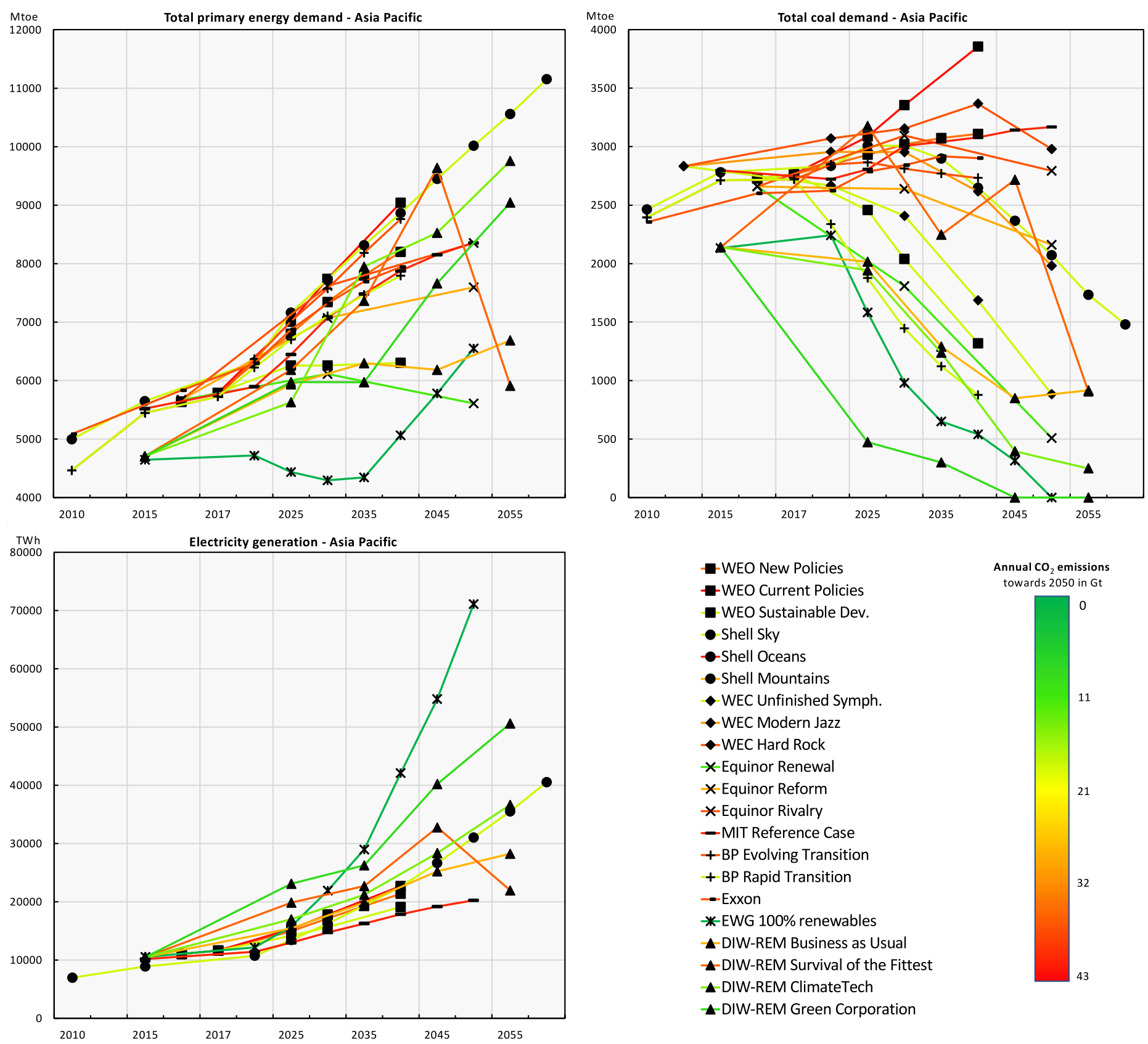

Figure 4: Total primary energy demand, coal demand, and electricity generation in Asia-Pacific compared. Note: The colours of the lines reflect the annual CO2 emissions level in the final outlook year (in Gt CO2); Shell, Equinor, and BP numbers have been adjusted to match the regional disaggregation "Asia-Pacific" as defined by the IEA 


\subsection{North America}
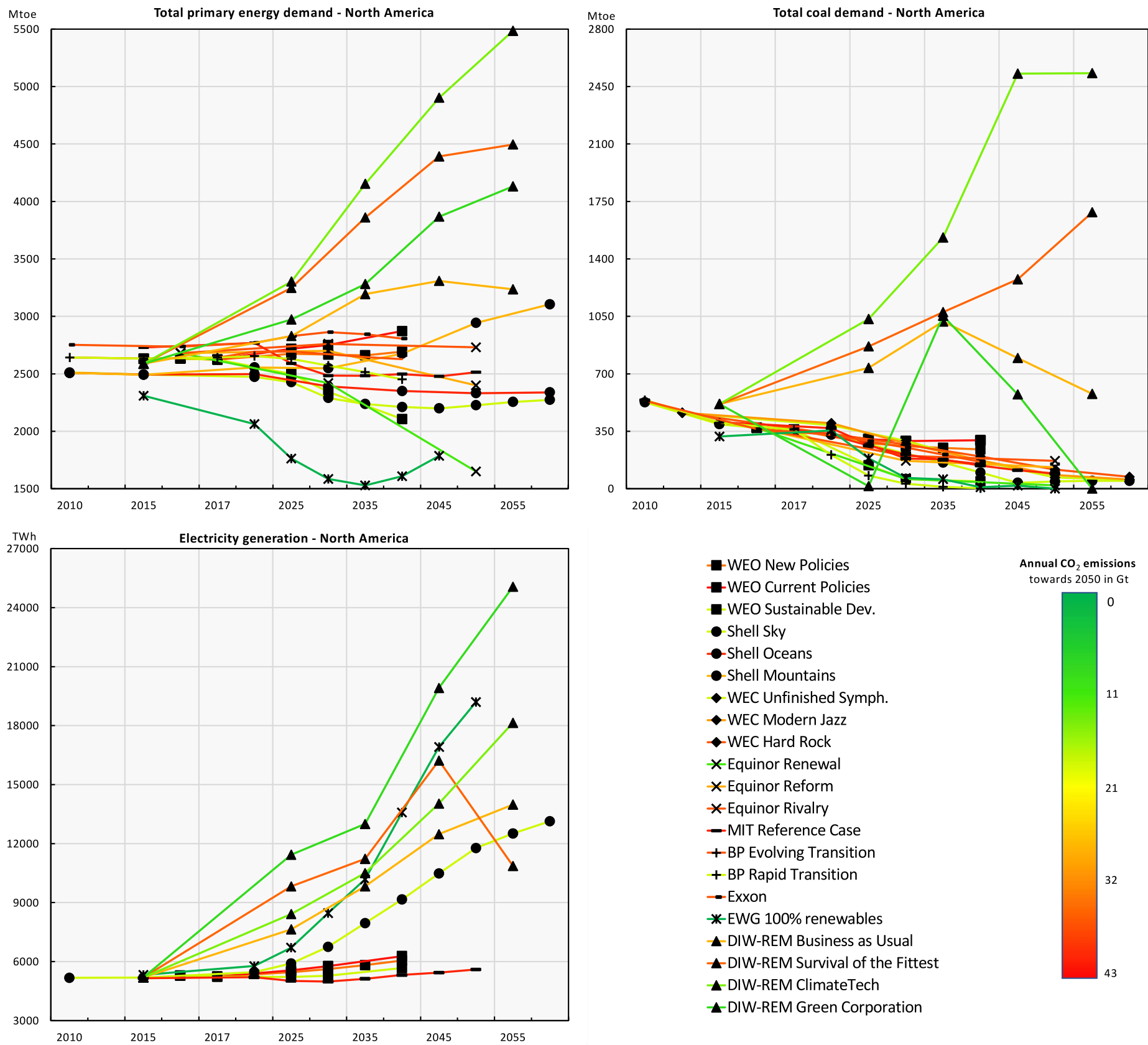

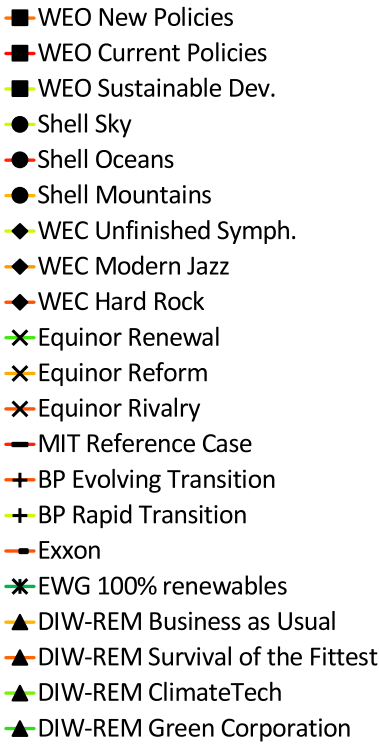

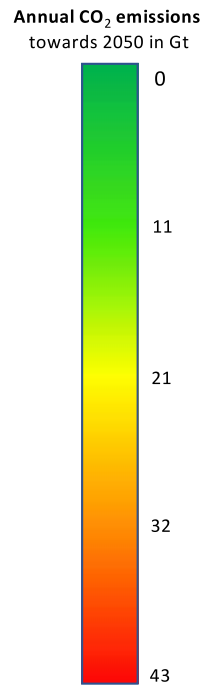

^-DIW-REM Green Corporation

Figure 5: Total primary energy demand, coal demand, and electricity in North America compared. Note: The colours of the lines reflect the annual CO2 emissions level in the final outlook year (in Gt CO2); BP numbers are adjusted to match the regional disaggregation "North America"

North America (Figure 5) has recently fostered its fossil fuel dependency, and it relies increasingly on domestic shale oil and gas (see, e.g., Ansari, 2019; Ansari and Kaufmann, 2019). Oil imports and domestic coal are therefore losing importance (Mendelevitch et al., 2019).

The trajectories of total North American primary energy demand resemble again the conic shape discussed before: The divergence of scenarios increases over time and almost symmetrically in both directions. At the lower end, we find a cloud of best-case scenarios (by EWG, Equinor, Shell, IEA), and the upper end of the range is taken by DIW-REM. The medium range contains all other scenarios and varies between slight decreases and increases in energy demand. Among them, ExxonMobil foresees the highest demand growth, and Shell's Ocean and Mountains, as well as MIT and Equinor's Renewal, come closer to the best-case scenarios. 
Total North American coal demand presents DIW-REM as a strong outsider: All DIW-REM scenarios observe an increase in demand, at least for the mid-term. This is connected to the strong role that CCS technology plays in Green Cooperation and ClimateTech, but also to the dominant role of US energy independence in the other two scenarios. The other outlooks exhibit modest to strong reductions in coal demand: Worst-case scenarios consider stagnating coal demand with some (minor) reduction towards 2050, while best-case scenarios and Shell's Mountains consider quicker decreases. Remarkably, towards 2060, Shell's Sky converges to a small yet positive level of coal demand, similar to the WEC outlook, which has reached Paris-compatible global emissions by then. This is an indicator that these scenarios also include negative emissions technologies, though without mentioning it transparently.

Electricity generation in North America shows more initial variation than its European and Asian counterparts. The DIW-REM outlook, again, shows large increases in the 2020 s, while the outlooks of MIT and IEA as well as Shell's Sky project no changes at first. Towards 2030, however, the outlooks part again with different growth rates. IEA and MIT continue to stay close to today's values, while Sky eventually witnesses strong increases. The EWG/LUT outlook starts with slow increases but finally catches up with our outlook.

\section{Discussion}

The overview has shown considerable differences between the different outlooks and scenarios. This section provides a discussion on selected topics mentioned in the previous sections and regarding the scenario generation process in general.

\subsection{The qualitative dimension}

There is no apparent pattern according to which an outlook's qualitative elaboration (storyline and drivers) affects the numerical trajectories. However, based on the observations, we raise two concerns:

First, some of the scenarios with more extreme trajectories have a weak qualitative background, making their eventual feasibility and plausibility questionable. The EWG/LUT scenario is an outlier regarding most indicators. Its normative nature - it eventually targets a $100 \%$ renewable world explains this behaviour. Nevertheless, the scenario's missing qualitative elaboration limits its utility: It fails to explain how we eventually reach such a world; it treats the energy system as isolated from social, political, and economic developments. Two other examples exist: Also BP's Rapid Transition contains a surprisingly fast coal phase-out without providing a story of how this takes place. Equinor's Renewal has a moderate qualitative background, but its pattern of green growth is not led by decarbonisation but by declining rates of primary energy demand. Such a development would require substantial energy efficiency improvements and decoupling economic growth from energy demand; the plausibility of this may be controversial. In all three cases, a strong qualitative background (i.e. storyline and transparent drivers) would strengthen the respective scenarios (by proving its social, political, and economic feasibility) or potentially motivate a revision.

Second, indicators of scenarios with a stronger qualitative background seem to show higher fluctuations throughout the scenario period. Whereas most scenarios with no or little storyline and driver setup exhibit monotonous paths, their counterparts show both increases and decreases over their time horizons. We argue that this volatile behaviour reflects the inclusion of the nonmonotonicities that can be found in the "soft" factors (i.e. society, policy, etc.) behind the energy system; the qualitative elaboration might eventually enable modellers to choose their quantitative implementation in a way that reflects these developments better.

Most outlooks with a strong qualitative elaboration are set up in a worst/base/best-case setup. Shell's scenarios contain the most sophisticated qualitative elaboration and are a refreshing counterexample to this trend. They assume very nuanced drivers and provide ambiguous worlds beyond 'best' and 'worst'. Their numerical indicators, however, diverge from other outlooks - which could be either be the reward for the strong qualitative elaboration or the result of potential weaknesses in data and model. Unfortunately, cross-validation of outlooks hardly is an option due to the use of proprietary models and data. It is impossible to evaluate to which extent outlooks are 
independent of each other, or whether anchoring effects, group thinking, and shared data sources make outlooks prone to common biases. There is no way to tell whether similarities between scenarios occur because they eventually reflect a plausible version of the future, or whether they have all been influenced by each other.

\subsection{Regional analysis}

Another set of observations concerns the global/regional divide. While the different outlooks provide a diversified picture on the global level, the trajectories on the regional level seem less deliberate. Some regional trajectories (e.g. Equinor, Shell, and DIW-REM in Europe; IEA in North America) do not show convergence based on the respective outlook to which they belong. In other words, whereas global trajectories are mostly segregated between best and worst cases, regional trajectories are sometimes rather grouped by their issuing institution. In other cases (e.g. EWG/LUT), regional trajectories seem to mimic global developments. Moreover, the range of possible developments given by the scenarios on the regional level is not smaller than on the global level; instead, the variation is even larger in most cases.

This observation might be connected to an increased level of complexity: Generating scenarios starts typically on the global level, and regions are only elaborated in a second step. Hence, regional trajectories are the uncertain result of uncertain global dynamics, making the scenario cone even wider for the regional level. The results are more pronounced with respect to the outlook's underlying assumptions. Moreover, the numerical calibration of regions might receive less attention than the global level (which is typically more visible to a broad audience), making the scenarios less plausible and, thus, less reliable. In general, while some outlooks provide a good regional disaggregation, others fail to do so. For example, the BP outlook does not feature any regional disaggregation except for exemplary country analyses.

Yet, a top-down approach to regional analysis is also questionable from a conceptual perspective. It is eventually the regional level (including national interests and policies) that shapes much of the global sphere. Therefore, global top-down visions risk providing inconsistent pictures. This could be circumvented by starting the analysis on the regional level and constructing the global dimension by aggregation. However, this may require efforts and time beyond the capacities of outlook teams.

\subsection{Climate change mitigation}

Regarding the success of climate change mitigation, our survey provides dismal perspectives. No scenario that extrapolates current trends (i.e. business-as-usual scenarios) foresees limiting global warming to below $2^{\circ} \mathrm{C}$. Eventually, only best cases and normative scenarios with explicit climate targets are compliant with the Paris Agreement. Hence, all outlooks agree that the world is currently on a path that fails to prevent climate change. This finding is identical to the conclusion of Dagnachew et al. (2019).

Moreover, the survey shows that there is not one unique vision of a Paris-compatible world and that (non-emission) indicators could be misleading. While some scenarios with successful climate change mitigation consider a world based on renewables, others continue to include fossil fuels in the energy mix. The first group includes the EWG/LUT scenario, DIW-REM's Green Cooperation, and, to a lesser extent, Shell's Sky: In these futures, the energy system undergoes a deep decarbonisation, and fossil fuels are to a large extent- if not fully -replaced by renewables. The second group includes the best cases of IEA, WEC, DIW-REM's ClimateTech, and, to a lesser extent, Equinor: Here, global emissions are curbed, but fossil fuels remain a central element in the energy system. These worlds are only feasible under the assumption of breakthroughs in CCS and negative emission technologies, which are commonly assumed in energy outlooks. This bears two problems: First, energy outlooks tend to have a myopic technology focus on single technologies, often linked to the traditional focus of the publishing institution (e.g. fossil fuels, CCS). Hence, they may neglect the impact of other technological (e.g. synthetic fuels, hydrogen) or social developments. Moreover, outlooks are rarely transparent regarding their technological assumptions, making such bias hard to identify. Of course, similar remarks can be given with regard to the feasibility of $100 \%$ renewable energy systems (Heard et al., 2017). 
Our observations suggest that the share of renewables is not a strong signal for successful climate change. While some scenarios with high shares of renewables fail to curb emissions (e.g. DIW-REM Business as Usual), other scenarios with lower renewable shares eventually succeed in it (e.g. DIWREM ClimateTech, WEC Unfinished Symphony, IEA's Sustainable Development).

The survey has also shown that primary energy demand is an unfit indicator for successful climate change mitigation. While some climate-friendly scenarios consider a stagnation of primary energy demand (Equinor's Renewal, IEA Sustainable Development, WEC Modern Jazz), others exhibit growth rates of primary energy demand even above those of other futures without successful climate change mitigation (DIW-REM Green Cooperation, Shell's Sky, EWG/LUT).

On a side note, our observations confirm that IEA WEO seems overly conservative in certain regards. Among all scenarios analysed, the Current Policies scenario has the lowest share of renewables, and even the New Policies scenario features considerably lower renewables numbers than most business-as-usual scenarios. While the strong importance of natural gas towards 2050 is also seen in other outlooks, the IEA WEO foresees a particularly strong future role for coal, while electricity demand increases only slightly. Moreover, the variation between scenarios within the WEO (including Sustainable Development) is low compared to other outlooks.

\subsection{Transparency and accounting}

The lack of transparency is a general and omnipresent issue in energy outlooks. While it is reasonable that not all modellers are able to publish their data or model equations, it is counterintuitive that some outlooks do not even outline their methods. IEA, WEC, DIW-REM, MIT, and EWG/LUT are the only outlooks that provide model documentations, and Shell's outlook comes at least with a verbal description of the model. The other outlooks do not provide any information on their methods.

Other studies raise similar concerns, remarking that scenarios lack transparency in assumptions, methods, and drivers (Ernst et al., 2018). Without carefully scrutinising energy outlooks, in many cases, it is even impossible for readers to distinguish inputs and assumptions from endogenous model outputs.

Moreover, differences in accounting and data sources lead to considerable differences between outlooks, even for the base year. Therefore, comparing numbers between outlooks is not trivial. Without considering the entire trajectory and initial levels, wrong conclusions could result.

\section{Summary and conclusions}

This article has presented a survey of prominent energy outlooks (IEA, WEC, Royal Dutch Shell, Equinor, BP, ExxonMobil, MIT, EWG, and our own outlook, DIW-REM) and shed light on the similarities and differences between them. With this, we have aimed at providing a compact survey of the outlooks, collecting observations, and elaborating on the new DIW-REM outlook.

Meta information on the scenarios and energy system indicators (primary energy demand and fuel shares on the global and the regional level) have been collected in tables and figures which provide compact overviews for interested readers. We make several observations that may inspire future research.

First, the various outlooks exhibit different degrees of an elaborate qualitative side (in terms of storyline, drivers). Nevertheless, there is no clear pattern as to whether outlooks with a strong qualitative foundation would entail fundamentally different trajectories. We have found, however, that some of the outlooks with a stronger qualitative side show more mid-term fluctuations, i.e. their numerical trajectories tend to be non-monotonous, potentially as a result of the qualitative input. Moreover, we suggest that missing a qualitative elaboration makes it harder to assess a scenario's social, technological and political feasibility. In general, we wish to emphasise that less sophisticated frameworks of qualitative elaboration such as the Shared Socioeconomic Pathways ("SSPs", see e.g. O'Neill et al., 2014; Riahi et al., 2017) are improvements towards the inclusion of social and economic factors in energy scenarios; however, they do not meet the high standards set by, for 
instance, qualitative foresight methods. Thus, SSP-style frameworks are subject to the same concerns.

Second, to varying degrees, world-wide outlooks seem to neglect the regional dimension. This manifests in varying degrees of regional coverage (some outlooks provide virtually no regional numbers or developments) but also in the quality of the numerical indicators. Many regional trajectories towards 2050 are grouped more by outlooks (i.e. the responsible institutions) than by content (e.g. best cases vs. worst cases).

Third, regarding the success of climate change mitigation, our observations suggest that $2^{\circ} \mathrm{C}$ scenarios foresee not only low-carbon worlds with a focus on renewables but also futures with persistent fossil fuels. Similarly, the different outlooks provide ambiguous pictures regarding the role of energy demand and specific fuel shares, making them imperfect indicators for tracking climate change mitigation. Of course, in this study, we have not considered or analysed the eventual feasibility or plausibility of individual outlooks but taken each one as given. Moreover, our survey backs the observations that current paths are incompatible with the Paris Agreement's $2^{\circ} \mathrm{C}$ target.

Fourth, our observations have raised concerns about a lack of transparency in data and methods but also about differences in accounting across the outlook spectrum.

Our DIW-REM outlook provides bold visions of the future. Its setup is similar to the WEC and Equinor outlook, which were developed around the same time. They emphasise the role of international policy, coordination, and connecting climate change mitigation to social targets such as poverty eradication in the developing world. This common approach sends a strong message towards policymakers. The numbers of our outlook on the global level are progressive but match other outlooks. Nevertheless, some regional results diverge significantly as a result of different regional foci in scenario development and modelling.

Lastly, we emphasise that the remarks made in this paper do not aim at belittling or defaming any particular outlooks. Instead, this paper aims at providing comparable input and stimulating a discussion about energy outlooks and their reception in general. We envision that further research and - even more so - a larger discussion on the role of scenarios and outlooks will be beneficial for both modellers and decision-makers.

\section{References}

Amer, M., Daim, T.U., Jetter, A., 2013. A review of scenario planning. Futures 46, 23-40.

Ansari, D., 2017. OPEC, Saudi Arabia, and the shale revolution: Insights from equilibrium modelling and oil politics. Energy Policy 111, 166-178.

Ansari, D., 2019. Rigging economics. Nature Energy 4, 263-264.

Ansari, D., Holz, F., 2019. Anticipating global energy, climate and policy in 2055: Constructing qualitative and quantitative narratives. Energy Research \& Social Science 58, 101250.

Ansari, D., Holz, F., al-Kuhlani, H., 2019. Energy, climate, and policy towards 2055: An interdisciplinary energy outlook (DIW-REM Outlook). DIW Berlin: Politikberatung kompakt.

Ansari, E., Kaufmann, R.K., 2019. The effect of oil and gas price and price volatility on rig activity in tight formations and OPEC strategy. Nature Energy, 1.

BP, 2019. BP Energy Outlook. https://www.bp.com/content/dam/bp/businesssites/en/global/corporate/pdfs/energy-economics/energy-outlook/bp-energy-outlook-2019.pdf.

Braunreiter, L., Blumer, Y.B., 2018. Of sailors and divers: How researchers use energy scenarios. Energy Research \& Social Science 40, 118-126. 
Burrows, M.J., Gnad, O.J.F., 2018. Between 'muddling through'and 'grand design': Regaining political initiative-The role of strategic foresight. Futures 97, 6-17.

Carrington, G., Stephenson, J., 2018. The politics of energy scenarios: Are International Energy Agency and other conservative projections hampering the renewable energy transition? Energy Research \& Social Science 46, 103-113.

Child, M., Koskinen, O., Linnanen, L., Breyer, C., 2018. Sustainability guardrails for energy scenarios of the global energy transition. Renewable and Sustainable Energy Reviews 91, 321-334.

Cochran, J., Mai, T., Bazilian, M., 2014. Meta-analysis of high penetration renewable energy scenarios. Renewable and Sustainable Energy Reviews 29, 246-253.

Dagnachew, A.G., Hof, A.F., Lucas, P.L., van Vuuren, D.P., 2019. Insight into Energy Scenarios: A comparison of key transition indicators of $2^{\circ} \mathrm{C}$ scenarios. PBL Netherlands Environmental Assessment Agency.

Deason, W., 2018. Comparison of $100 \%$ renewable energy system scenarios with a focus on flexibility and cost. Renewable and Sustainable Energy Reviews 82, 3168-3178.

Derbyshire, J., 2017. Potential surprise theory as a theoretical foundation for scenario planning. Technological Forecasting and Social Change 124, 77-87.

Equinor, 2019. Energy Prespectives 2019 long-term macro and market outlook. https://www.equinor.com/content/dam/statoil/documents/energyperspectives/Energy\%20Perspectives\%202019\%20report.pdf.

Ernst, A., Biss, K.H., Shamon, H., Schumann, D., Heinrichs, H.U., 2018. Benefits and challenges of participatory methods in qualitative energy scenario development. Technological Forecasting and Social Change 127, 245-257.

ExxonMobil, 2018. Outlook for Energy: a view to 2040. https://corporate.exxonmobil.com/Imedia/Global/Files/outlook-for-energy/2018-Outlook-for-Energy.pdf.

Godet, M., Roubelat, F., 1996. Creating the future: the use and misuse of scenarios. Long range planning 29, 164-171.

Heard, B.P., Brook, B.W., Wigley, T.M., Bradshaw, C.J., 2017. Burden of proof: A comprehensive review of the feasibility of $100 \%$ renewable-electricity systems. Renewable and Sustainable Energy Reviews 76, 1122-1133.

Heuer, R.J., Pherson, R.H., 2015. Structured Analytic Techniques for Intelligence Analysis, Second edition ed. SAGE Publications, London, United Kingdom.

Holz, F., Richter, P., Egging, R., 2015. A Global Perspective on the Future of Natural Gas: Resources, Trade, and Climate Constraints. Review of Environmental Economics Policy 9, 85-106.

Huppmann, D., Egging, R., 2014. Market power, fuel substitution and infrastructure-A large-scale equilibrium model of global energy markets. Energy 75, 483-500.

IEA, 2018a. World Energy Dodel Documentation. https://www.iea.org/media/weowebsite/energymodel/WEM2018.pdf.

IEA, 2018b. World Energy Outlock. https://webstore.iea.org/world-energy-outlook-2018.

Iyer, G., Edmonds, J., 2018. Interpreting energy scenarios. Nature Energy 3, 357. 
Krey, V., 2014. Global energy-climate scenarios and models: a review. Wiley Interdisciplinary Reviews: Energy and Environment 3, 363-383.

Kwon, P.S., Østergaard, P.A., 2012. Comparison of future energy scenarios for Denmark: IDA 2050, CEESA (coherent energy and environmental system analysis), and climate commission 2050. Energy 46, 275-282.

Lucena, A.F., Clarke, L., Schaeffer, R., Szklo, A., Rochedo, P.R., Nogueira, L.P., Daenzer, K., Gurgel, A., Kitous, A., Kober, T., 2016. Climate policy scenarios in Brazil: A multi-model comparison for energy. Energy Economics 56, 564-574.

Lund, H., Arler, F., Østergaard, P., Hvelplund, F., Connolly, D., Mathiesen, B., Karnøe, P., 2017. Simulation versus optimisation: Theoretical positions in energy system modelling. Energies 10, 840.

Martinot, E., Dienst, C., Weiliang, L., Qimin, C., 2007. Renewable energy futures: Targets, scenarios, and pathways. Annu. Rev. Environ. Resour. 32, 205-239.

Mendelevitch, R., Hauenstein, C., Holz, F., 2019. The death spiral of coal in the US: will changes in US Policy turn the tide? Climate Policy 19, 1310-1324.

Mendonça, S., e Cunha, M.P., Kaivo-oja, J., Ruff, F., 2004. Wild cards, weak signals and organisational improvisation. Futures 36, 201-218.

Mercer, D., 1995. Scenarios made easy. Long range planning 28, 7-86.

Metayer, M., Breyer, C., Fell, H.-J., 2015. The projections for the future and quality in the past of the World Energy Outlook for solar PV and other renewable energy technologies. 31st European Photovoltaic Solar Energy Conference and Exhibition.

Mietzner, D., Reger, G., 2005. Advantages and disadvantages of scenario approaches for strategic foresight. International Journal Technology Intelligence and Planning 1, 220-239.

O’Neill, B.C., Kriegler, E., Riahi, K., Ebi, K.L., Hallegatte, S., Carter, T.R., Mathur, R., van Vuuren, D.P., 2014. A new scenario framework for climate change research: the concept of shared socioeconomic pathways. Climatic change 122, 387-400.

Paltsev, S., 2017. Energy scenarios: the value and limits of scenario analysis. Wiley Interdisciplinary Reviews: Energy and Environment 6.

Quarton, C.J., Tlili, O., Welder, L., Mansilla, C., Blanco, H., Heinrichs, H., Leaver, J., Samsatli, N.J., Lucchese, P., Robinius, M., 2020. The curious case of the conflicting roles of hydrogen in global energy scenarios. Sustainable Energy \& Fuels.

Ram, M., Bogdanov, D., Aghahosseini, A., Gulagi, A., Oyewo, A., Child, M., Caldera, U., Sadovskaia, K., Farfan, J., Barbosa, L., 2019. Global energy system based on 100\% renewable energy-power, heat, transport and desalination sectors. Study by Lappeenranta University of Technology and Energy Watch Group, Lappeenranta, Berlin.

Ramírez, R., Selin, C., 2014. Plausibility and probability in scenario planning. Foresight 16, 54-74.

Reilly, J., Prinn, R., Chen, H., Sokolov, A., Gao, X., Schlosser, A., Morris, J., Paltsev, S., 2018. 2018 Food, Water, Energy and Climate Outlook. MIT Joint Program. https://globalchange.mit.edu/sites/default/files/newsletters/files/2018-JP-Outlook.pdf.

Riahi, K., Van Vuuren, D.P., Kriegler, E., Edmonds, J., O'neill, B.C., Fujimori, S., Bauer, N., Calvin, K., Dellink, R., Fricko, O., 2017. The shared socioeconomic pathways and their energy, land use, 
and greenhouse gas emissions implications: an overview. Global Environmental Change 42, 153168.

Schoemaker, P.J., 1995. Scenario planning: a tool for strategic thinking. Sloan management review 36, 25.

Shell, 2013. New Lens Scenarios a Shift in Perspective for a World in Transition. https://www.shell.com/content/dam/royaldutchshell/documents/corporate/scenarios-newdoc.pdf.

Shell, 2018. Shell Scenarios SKY meeting the goals of the paris Agreement. https://www.shell.com/promos/business-customers-promos/download-latest-scenariosky/ jcr content.stream/1530643931055/eca19f7fc0d20adbe830d3b0b27bcc9ef72198f5/shellscenario-sky.pdf.

Silberglitt, R., Hove, A., Shulman, P., 2003. Analysis of US energy scenarios: meta-scenarios, pathways, and policy implications. Technological Forecasting and Social Change 70, 297-315.

Söderholm, P., Hildingsson, R., Johansson, B., Khan, J., Wilhelmsson, F., 2011. Governing the transition to low-carbon futures: A critical survey of energy scenarios for 2050 . Futures $43,1105-$ 1116.

Sokolov, A.P., Schlosser, C.A., Dutkiewicz, S., Paltsev, S., Kicklighter, D.W., Jacoby, H.D., Prinn, R.G., Forest, C.E., Reilly, J.M., Wang, C., 2005. MIT integrated global system model (IGSM) version 2: model description and baseline evaluation. MIT Joint Program on the Science and Policy of Global Change.

Sorrell, S., Miller, R., Bentley, R., Speirs, J., 2010. Oil futures: A comparison of global supply forecasts. Energy Policy 38, 4990-5003.

Subramanian, A., Gundersen, T., Adams, T., 2018. Modeling and simulation of energy systems: A review. Processes 6, 238.

Van Notten, P., 2005. Writing on the wall: Scenario development in times of discontinuity. UniversalPublishers.

Wack, P., 1985. Scenarios: uncharted waters ahead. Harvard Business Review SeptemberOctober.

Weber, C., McCollum, D.L., Edmonds, J., Faria, P., Pyanet, A., Rogelj, J., Tavoni, M., Thoma, J., Kriegler, E., 2018. Mitigation scenarios must cater to new users. Nature Climate Change 8, 845.

WEC, 2016. World Energy Scenarios the grand transition. In collaboration with Accenture Strategy and Paul Scherrer Institute. https://www.worldenergy.org/wp-content/uploads/2016/10/WorldEnergy-Scenarios-2016 Full-Report.pdf.

Wiek, A., Keeler, L.W., Schweizer, V., Lang, D.J., 2013. Plausibility indications in future scenarios. International Journal of Foresight and Innovation Policy 9, 3.

Wilkinson, A., Kupers, R., 2013. Living in the futures. Harvard business review 91, 118-127. 